\title{
Income Levels and Farm Economic Viability in Italian Farms: An Analysis of FADN Data
}

\author{
Adele Coppola ${ }^{1, *}$, Alfonso Scardera ${ }^{2}$, Mario Amato ${ }^{3}{ }^{-1}$ and Fabio Verneau ${ }^{3}$ \\ 1 SAFE-School of Agricultural, Forestry, Food and Environmental Sciences, Università degli Studi della \\ Basilicata, 85100 Potenza, Italy \\ 2 CREA-Research Centre for Agricultural Policies and Bioeconomy, 00198 Roma, Italy; \\ alfonso.scardera@crea.gov.it \\ 3 Department of Political Sciences, Università degli Studi di Napoli Federico II, 80138 Napoli, Italy; \\ mario.amato@unina.it (M.A.); verneau@unina.it (F.V.) \\ * Correspondence: adele.coppola@unibas.it; Tel.: +39-0971205433
}

Received: 13 May 2020; Accepted: 12 June 2020; Published: 16 June 2020

\begin{abstract}
In the European Union legislative proposals for the next Common Agricultural Policy (CAP) the income support remains an essential part of the CAP. This paper analyses agricultural income levels, the role of EU aids in ensuring fair levels of income and how different socio-economic and structural characteristics affect farms' economic viability. Italian Farm Accountancy Data Network (FADN) data have been processed and economic viability has been assessed by comparing Farm Net Income to a reference income and by estimating a profitability index to check whether the agricultural activities remunerate factors owned by the farmer and his/her family. After an explorative analysis, two multinomial logit models have been estimated to evaluate how structural and socio-economic characteristics affect the likelihood of a farm to be viable with and without EU aids. Both structural farm characteristics and farmer's production strategies explain the likelihood of a farm to be viable in the short and in the medium-long term. Farms are more likely to be viable as the size increases and the higher the capital intensity, while viability likelihood decreases with the farmer's age, when the holder is a woman, and the farm is localized in Southern Italy. CAP payments do not modify the factors that affect farm viability but can change their weight.
\end{abstract}

Keywords: farm income; economic viability; FADN; CAP; opportunity cost

\section{Introduction}

In 2018, the European Union (EU) Commission presented the legislative proposals on the Common Agricultural Policy (CAP) beyond 2020. Income support will still remain an essential part of the next EU policy, but under the new EU approach intervention needs to be more focused to those who are actively farming to earn their living. In this context, a key issue is how to identify which incomes should be taken into account and what weight agricultural and non-agricultural activities should have on total income.

This work aims at analysing this issue with reference to Italian agriculture. In particular, it aims to answer the following questions:

- How many farms achieve adequate income levels and are likely to persist in the medium-long term? How structural and socio-economic characteristics affect farm viability?

- What role do CAP payments play in determining the economic viability of farms?

In the following, data from the Italian Farm Accountancy Data Network (FADN) were used to provide an overview of income levels in Italian agriculture and the relevance of EU aids to ensuring 
adequate income levels. Farm Net Income (FNI) compared with a reference value was the base to evaluate the short-term viability of the farm. As the viability of farms is determined by both income levels and income fluctuations [1], to take account of income fluctuations, the analysis considered holdings that were included in the FADN sample for the three consecutive years 2015, 2016, and 2017 and the average data for the three-year period. Subsequently, a profitability index was used, with and without CAP aids, to check whether farms remunerate their resources and guarantee an adequate income for agricultural households in the medium-long term. Income and profitability levels have been the basis for assessing the viability of farm in the short and medium-long term, both with and without CAP payments, and for estimating the extent to which different farm and farmer characteristics influence the probability of a farm to be viable.

The organization of work is as follows. The next section outlines the conceptual framework of the work by highlighting the main issues related to the implementation of CAP support after 2020 . Section 3 describes the data and the method used. Sections 4 and 5 present the main results and concluding considerations.

\section{Ensuring "Fair" Incomes}

Over the last decades, the CAP objectives and instruments have progressively changed to adapt to the evolution of economic and agricultural systems and the emergence of new social demand for quality, health and environment. The way in which this change has occurred can be referred to as a "gradual reformism" approach, which over time has led to the inclusion of new objectives and measures and the adaptation of previous ones. As a result, the CAP has evolved from a sectoral policy to a policy that aims to integrate productive, social, and environmental objectives. Despite the broadening of the CAP goals, farms and farmers remain the main beneficiaries of this policy, although there is no doubt that, in order to be effective, social, environmental, and sectoral policies should focus on different targets (families or social groups, territories and resources, specific farm's typologies or farming systems). Indeed, the integration of new objectives has made it possible to maintain the EU agricultural policy approach and has been a way of justifying farmers' support at a time when their economic weight was progressively decreasing.

The EU proposals for the next programming phase introduce the so-called new delivery model but retain most of the past objectives. In particular, nine key objectives have been set, including ensuring a fair agricultural income, increasing competitiveness, supporting generational renewal and keeping vibrant rural areas, as well as rebalancing the power in the food chain and objectives relating to climate change, environment, landscape, and health.

Therefore, the goal of ensuring a fair income for farmers, stated in the 1957 Treaty of Rome, will remain one of the objectives of the CAP after 2020. According to the Treaty on European Union, increasing the income of people engaged in agriculture is the way to ensure a fair standard of living for the agricultural community. Therefore, agricultural policy acts on farmers but aims at the welfare of the agricultural community as a whole.

This approach and the way in which the CAP has been implemented so far, with support mainly linked to production and more recently to the land, have some critical points. Firstly, the policy focuses on self-employment and neglects hired workers who are also part of the agricultural community. This is because most European agriculture is based on family farms, where entrepreneurial income largely reflects the income of farm households, and the hired labour falls more within national intervention [2]. Secondly, CAP support is not linked to well-defined target income or household types, but also reaches farmers whose agricultural activity represents only a small proportion of overall economic activity or whose main business activity is not agricultural. In fact, EU support to agricultural incomes has been implemented without a clear picture of the various components defining the "standard of living" of the agricultural community and the incomes to be taken into account, and there is no statistical system able to provide comprehensive data and information on them [2]. Thirdly, CAP support has been 
unevenly distributed, with $20 \%$ of farms (the biggest ones) receiving $80 \%$ of the payments which is difficult to reconcile with the objective of ensuring a fair income.

As a fact, although ensuring fair income has been set as a founding objective since the early days of the CAP, it has never been precisely defined and this reflected in the lack of a well-defined operative target [3]. In fact, the term "fair" is rather vague and when it refers to income it may refer to the concept of equity, and thus be synonymous with "just" or "equal," or it may be understood as "appropriate," "adequate," or "reasonable". In both meanings, it is necessary to have a reference term against which the fairness or adequacy of agricultural income is measured.

In the studies dealing with issues related to farm incomes, in particular the poverty issue and the parity issue, the income fairness has been addressed by looking at the gap between farmers' incomes, on the one hand, and, on the other hand, the average wage in the economy [4], the average wage in the agricultural [5] or in non-agricultural sectors [6], the incomes of non-agricultural households as a whole, or those of the non-agricultural self-employed households [7-9]. Hill [10] points out that the standard of living of a farmer and his family depends not only on the flow of income, but also on their wealth. In fact, wealth has an equivalent in terms of income flow and it has to be considered when comparing the well-being level of different groups, especially if the comparison must result in choices regarding the support to be provided.

When the focus was on the issue of the ability of agricultural activity to reward the entrepreneur and his family or to guarantee adequate incomes that would allow the persistence of the farm in the medium-long term, the term of comparison has taken into account the opportunity cost of the factors conferred by the farmer $[1,11,12]$. Some studies analysing the problem of farm viability have assessed the adequacy of farm incomes as the ability to remunerate the labour force of the farmer and his family at a comparable wage in alternative activities [7], or have measured farm viability in relation to the ability to remunerate family work at the average agricultural wage and capital invested at an average rate of return [13-15]. This approach is certainly partial because farm viability is linked to the overall income level of the agricultural family, to which pluri-activity, pensions, or other sources of income outside the farm also contribute. Hennessy, Shresthra, and Farrel [15] distinguish the concept of viability from that of economic sustainability, where a farm is sustainable when it is not economically viable on the basis of farm income but is so thanks to the presence of other sources of income outside the farm.

A critical point in the definition of fair agricultural income is the source of the data to be considered. At the microeconomic level, the two main sources of information on farm incomes are agricultural accounting surveys and household budget surveys. At EU level, the Farm Accountancy Data Network (FADN) collects data on agricultural activities and allows the measurement of the net value added of the agricultural holding (i.e., the total value of production less intermediate consumption and depreciation) and the net agricultural income of the holding or the household income (the net value added of the holding minus wages, rents, and interest paid). Over the years, FADN data have included more information on the non-agricultural activities of the farmer and his/her family but are still not sufficient to calculate household income as a whole and to identify agricultural households, i.e., households for which agriculture is the main source of income. This information can best be obtained from household budget surveys, such as European Union Statistics on Income and Living Conditions (EU-SILC), which focus on the household, all members' incomes, and their living conditions. Based on EU-SILC, some studies have investigated the difference between agricultural and non-agricultural incomes, mainly in order to verify whether a difference exists, i.e., to address the issue of equal income $[7,9,16,17]$, or to assess the income situation and the risk of poverty (the issue of poverty) [18]. EU-SILC provide information on the disposable income of the agricultural household, a concept linked to the standard of living which is the objective of the CAP. However, this information is unlikely to be integrated into the business analysis.

Therefore, while EU-SILC can be useful for assessing social needs and could be used to define the profile of farmers, issues of farm viability and economic sustainability are better based on farm accounts 
data. This second approach has been chosen in this work on the basis of two main considerations. First, although the objectives refer to the standard of living of rural communities, the CAP intervenes at farm level and, therefore, a targeted intervention cannot be separated from the analysis of the specific income situation of the farm. Secondly, the vitality of the socio-economic fabric of rural areas is necessarily linked to the vitality of farms and the profitability of agricultural activity. The ability of farms to guarantee an adequate level of income is, in fact, a basic requirement for the maintenance of a dynamic socio-economic fabric in rural areas. The approach followed does not allow, therefore, to evaluate the standard of living of the agricultural community $[7,19]$. Nevertheless, it can give information on how agricultural activity contributes to the incomes of rural households, and the role agriculture can play in maintaining a dynamic socio-economic fabric.

In the following, the farm viability has been analysed distinguishing between the short and medium-long term. In the short term, a holding has been considered viable to the extent that it is able to ensure a level of income per family work unit at least equal to a given reference income. In the medium-long term, the level of income must also adequately remunerate all the factors owned by the farmer and his/her family at their opportunity cost. Only in this case, in fact, farmers will continue to invest in the sector in the medium-long term, contributing to maintain a lively socio-economic fabric in rural areas.

\section{Materials and Methods}

\subsection{The Data}

The analysis was carried out using Italian FADN average data for the three-year period 2015-2017. These data include structural and economic information on about 10 thousand farms per year whose economic size is more than 4000 euros of standard production. The analysis was focused on individual farms and simple societies for which the net agricultural income can be directly related to the family. Only farms included in the sample for the entire three-year period 2015-2017 were considered, and after excluding observations with anomalous or missing data, the final sample accounts for 6270 farms. Having chosen to use a sub-sample, data are not more representative of the entire population. Nevertheless, the analysis of the data can provide useful indications on the size of the phenomena under examination and on the main structural and productive characteristics that influence economic viability in Italian agriculture.

Data on farm net income (FNI) and EU aids were analysed in order to draw a general picture of income levels in Italian agriculture, their adequacy and the relevance that CAP aids have in achieving satisfactory income levels. This step required a preliminary assessment of the reference income. As the FADN data do not provide information on income and household composition as a whole, the Farm Net Income was compared with the average annual net earnings of an Italian worker. More precisely, the comparison parameter was the average of net earnings of a single-member household and a single-income household with two children, equal to $€ 22,950$ (Eurostat data). It should be noted that direct taxation is not considered in the FNI, while it is deducted in the calculation of the average net income of a worker. This reflects in a relative overestimation of net agricultural income.

Analysing the Farm Incomes per family work unit of the FADN sample in the three-year period 2015-2017, the average net agricultural income is just above 39 thousand euros/year. This value is higher than the average net income of the economy (about 23 thousand euros), but it does not give a true picture of the Italian situation. In fact, the median value is 20.4 thousand euros, so at least $50 \%$ of Italian farms are below the reference income. In particular, 301 farms ( $4.8 \%$ of the sample) have a zero or negative agricultural income and without other sources of income they would not survive even in the short term, and $30 \%$ of the sample has an economic return of less than half the reference income.

EU aids significantly contribute to farm income, and in the three-year period 2015-2017, they represented $36 \%$ of the FNI on average. As expected, their weight varies according to production specialisation (Farming systems refer to the classification used by FADN. That is based on the farm 
specialization concept, defined as the share of Standard Output higher than 2/3 of the total farm Standard Output) and farm's size (Table 1). In particular, the highest values characterize Fieldcrops $(52 \%)$ and Mixed systems (69\%), while the weight is close to zero in Horticulture $(2 \%)$. As far as the farm size is concerned, medium and large farms are more dependent on EU aids: aids represent around $45 \%$ of the FNI in farms above 15 hectares, while they contribute only for $10 \%$ to the FNI in less than 5 hectares farms. Differences across farming systems and size classes are statistically different (Table A1, Appendix A).

Table 1. Descriptive statistics for the European Union aids on Farm Net Income ratio by different farming systems and farm's size (average percentage on 2015-2017 years).

\begin{tabular}{ccc}
\hline & Mean & Std Dev. \\
\hline Farming system & 52.2 & \\
Fieldcrops & 2.3 & 6.04 \\
Horticulture & 21.1 & 0.09 \\
Permanent crops & 32.9 & 0.95 \\
Grazing livestock & 21.3 & 1.34 \\
Granivores & 69.1 & 0.89 \\
Mixed & & 5.90 \\
Farm size & 10.5 & \\
Less than 5 hectares & 37.8 & 0.78 \\
5-15 hectares & 44.6 & 4.35 \\
15-40 hectares & 46.2 & 1.73 \\
More than 40 hectares & & 5.53 \\
\hline
\end{tabular}

\subsection{The Viability and Profitability Indexes}

To assess whether the farm is able to guarantee a fair income in the short term and take into account the overall work engagement of the farmer and his/her family in the agricultural activity, a viability index [6] was calculated given by:

$$
\mathrm{VI}=\mathrm{FNI}-\mathrm{IR} \times \text { FAWU }
$$

where IR represents the reference income and FAWU are the family annual working units.

Values of VI equal or higher than 0 indicate that the farm is ensuring to the family work an income level that is at least equal to alternative jobs and then the farm can be considered viable in the short term. Moreover, the higher is the index the more viable is the farm.

The analysis of the viability and sustainability in the medium-long term starts from the consideration that, in family farms, the entrepreneur, in addition to their work, also uses their own land and capital. In this case, the Farm Net Income represents the reward for all the family factors and the most suitable reference term is the remuneration of the factors at their opportunity cost. In this case, "fair income" should be understood as "remuneration that family factors would have in the best or possible alternative use." Following previous studies [20,21], a profitability index (PI) developed within the framework of the FADN was used, calculated as the ratio between the FNI and a Reference Net Income (RNI):

$$
\mathrm{PI}=\mathrm{FNI} / \mathrm{RNI}
$$

where RNI is given by the sum of the opportunity costs of all the farmer's family factors as follows:

$\mathrm{RNI}=\left(\right.$ family labour hours in a year ${ }^{*}$ hourly average agricultural wage $)+($ value of working capital * average annual return) + (value of land capital * average land rent)

The estimate of RNI is based, for the labour factor, on the national average hourly wage, net of social security contributions and gross of the severance indemnity, provided for qualified agricultural workers. The source of data are the annual tables relating to the average daily wages of agricultural workers 
for social security purposes, produced by the Ministry of Labour and Social Policies. With regard to the return on working capital of the farmer, the average annual return on government bonds (source: Ministry of Economy and Finance) is used net of tax charges, while the return on land capital is estimated as the ratio of the average values of land rental fees, recorded in the FADN Survey, and the relative values of land capital. The calculation criteria adopted for factor remuneration were set at $10.86 € / \mathrm{h}$ for family work, $2.0 \%$ for working capital and $1.7 \%$ for land.

The Profitability Index (PI) expresses an overall estimate of the farm's profitability. When PI is equal or higher than 1 the agricultural activity remunerates all the family factors at their opportunity costs and the farm can be considered viable in the medium-long term.

The viability and profitability indexes have been analysed in relation to some factors that are generally considered significant in affecting the efficiency and the factors productivity at the farm level and therefore could influence the income level and farm viability as a whole: (1) socio-demographic characteristics of the farmer, (2) structural characteristics of the farm, and (3) productive choices of the farmer.

Among socio demographic characteristics, we investigated farmer's age, gender, and education. It is widely acknowledged that more experienced and professional farmers have a more effective decision-making process which might affect the viability of their firms. Following previous scholars [22-24], the age of the farmer can be considered as an indicator of experience and skill, then can be related to the farm economic viability. The education level can push the farmer to adopt innovations and can positively affect farm management and productivity $[11,25,26]$, and several studies underlined how the productive role of the farm and the production intensity can differ across genders [27-29].

The structural characteristics include the farm size, the quality of land, the capital intensity, and the family commitment in the farm, among others. Farm size can influence efficiency and farm viability through scale's and scope's economies [30]. Moreover, the adoption of technological innovations which determine better farm performances can depend on the resulting benefits and those are linked to the farm size [31]. Capital intensity and land quality identify the firm's factor endowment in quantity or quality term, which directly affect the productivity [32]. The impact of the family labour on the productive performance is more controversial. According to some authors, the ratio of family to total labour has a negative effect on farm performance as family labour tends to be less experienced/efficient and farms with a higher share of hired workers are more productive [33]. Other studies state that the family involvement increases the farm performance because of a higher organisational efficiency [34]. Among structural characteristics, we also included the location of the farm. The location can affect the viability because of the infrastructures, the institutional environment, and the social capital that are related to the territory and can influence the competitiveness and the efficiency of the farm $[35,36]$. Moreover, farms located in disadvantaged areas, with a lower possibility of crop diversification and without adequate infrastructure, will have a high probability of being not viable as it has also been pointed out by the European Commission [37].

A third group of variables that are expected to influence farm performance and viability is related to productive choices under the direct control of the farmer. They can include the productive specialization, the income diversification in non-agricultural activities [38], and what van der Ploeg defined the deepening strategies [39], that is the valorisation of farm products through processing or direct sales, which represent a way to deliver products that entail more added value.

To verify the significance of the links between these characteristics and the ability of farms to remunerate their resources and to guarantee a satisfactory income, non-parametric Kruskal-Wallis (k-sample) and U Mann-Whitney (2-sample) tests were used which require no distributional assumptions.

The viability of farms in the short and medium-long term has been analysed by considering the farm income both gross and net of CAP aids in order to show to what extent farm results depend on CAP support. The comparison of data with and without aids does not take into account changes in farmers' behaviour if the support was removed, production adaptations and consequent changes in 
the structure of costs and revenues, as well as the effects that the removal of EU support could have on the factor market, in particular on land value $[1,40]$. Nevertheless, it can give indications on the contribution of the CAP to the objective of maintaining a fabric of economically viable farms and on the degree of vulnerability of Italian agriculture in relation to changes in support policies.

\subsection{The Econometric Analysis}

Given the assertion that more than one group is going to be highlighted by comparing the indexes and particular interest lies in the individual effects of explanatory variables on each outcome, a multinomial logit model will be performed, an extension of the binary logit model particularly useful when the dependent variable has more than two outcomes. Therefore, the outcome variable $y$ can take on the values $j=1,2, \ldots J$, with $J$ being a positive integer. In particular, the model explains the probability of being "unviable in both short and long term" $(j=1)$, "viable in short term but unviable in the long run" $(j=2)$, "unviable in the short term but viable in the long" $(j=3)$, and "viable in both short and long term" $(j=4)$. The determinants associated with each category can be contrasted with the base category, which is being "unviable in the short and long term" in our study, in order to underline how changes in the elements of $x$ affects the probabilities $P\left(y_{i}=j x\right), j=1,2, \ldots J[41]$. The probability of the $J$ categories is determined by the following equation:

$$
P\left(y_{i}=k \mid x_{i}\right)=\frac{\exp \left(\beta_{k} x_{i}\right)}{\sum_{j=1}^{j} \exp \left(\beta_{j} x_{i}\right)}, j=1,2, \ldots J,
$$

where $k$ is one of the $j$ subgroups and $P\left(y_{i}=k\right)$ is the probability that the $i$ th farm belongs to the $k$ subgroup and $x_{i}$ describes farm and farmers characteristics. Since constraints must be imposed, we assume that $\beta_{1}=0$ [42] so that is possible to identify the coefficients related to the base outcome. Yet, the model can be written as:

$$
\begin{gathered}
P\left(y_{i}=k \mid x_{i}\right)=\frac{\exp \left(\beta_{k} x_{i}\right)}{1+\sum_{j=2}^{j} \exp \left(\beta_{j} x_{i}\right)} \text { for } k>1, \\
P\left(y_{i}=1 \mid x_{i}\right)=\frac{1}{1+\sum_{j=2}^{j} \exp \left(\beta_{j} x_{i}\right)}
\end{gathered}
$$

The multinomial logit model is estimated using maximum likelihood with the following equation:

$$
L\left(\beta_{2}, \ldots, \beta_{j} \mid y, X\right)=\prod_{k=1}^{j} \prod_{y_{i}=k} \frac{\exp \left(\beta_{k} x_{i}\right)}{\sum_{j=1}^{j} \exp \left(\beta_{j} x_{i}\right)}
$$

where $\prod y_{i}=k$ is the product over all cases for which $y_{i}=k$ [42]. Coefficients are interpreted using the Relative Risk Ratios (RRR), which is the relative probability of $y_{i}=k$, for $k>1$ to the base category:

$$
\frac{P(y=k)}{P(y=1)}=\exp \left(\beta_{k} x_{i}\right) \text { for } k>1
$$

Furthermore, the model will be tested in the two different scenarios: with and without CAP aids. Therefore, in order to test the hypothesis that the estimates of Model 1 are statistically different from estimates of Model 2, a Seemingly Unrelated Estimation (SUEST) will be performed [43]. Since our models are fit on the same sample, so that the estimators are stochastically dependent, the SUEST command allows us to obtain the Wald test more efficiently by avoiding data manipulation. The null hypothesis is that the difference between the coefficients of the two models are equal to 0 (Model 1 coeff. - Model 2 coeff. $=0$ ). Therefore, the test highlights the differences of the effects of each independent variable between Model 1 and Model 2. 


\section{Results}

\subsection{Short and Long Term Viability in the FADN Sample}

The mean value of the viability index (VI) is equal to 22.4 thousand euro (Table A2, Appendix A). Therefore, farm activity is able to guarantee an adequate remuneration to labour, at least. Nevertheless, in 3411 farms (54\% of the sample), the index is negative, then in more than half of the sample the FNI is lower than the reference income to the family work. If FNI is net of EU payments, the Viability Index halves to 10.3 thousand euro. Therefore, the ability to guarantee the reference income weakens sharply when CAP aid is removed, and the area of short-term viability decreases from $46 \%$ to $34 \%$ of the sample. In relation to the role played by EU income payments, the viability area is not affected by aids when farms have less than 5 hectares, while farms with more than 40 hectares with FNI equal to or higher than the reference income decrease from $72 \%$ to $47 \%$ when EU aids are subtracted (Table 2). Among farming systems, the short-term viability depends to a large extent on EU aids for Fieldcrops, where the share of viable farms decreases from $41.4 \%$ to $22.4 \%$ when incomes are measured net of EU payments.

Table 2. Share of short-term and long-term viable farms with and without EU aids (\%) by farm's and farmer's characteristics.

\begin{tabular}{|c|c|c|c|c|}
\hline & \multicolumn{2}{|c|}{$\begin{array}{l}\text { Share of Short-Term Viable Farms } \\
\text { (Viability Index }>0 \text { ) }\end{array}$} & \multicolumn{2}{|c|}{$\begin{array}{l}\text { Share of Long-Term Viable Farms } \\
\text { (Profitability Index }>1 \text { ) }\end{array}$} \\
\hline & With EU Aids & Without EU aids & With EU Aids & Without EU Aids \\
\hline \multicolumn{5}{|l|}{ Farming system } \\
\hline Fieldcrops & 41.4 & 22.4 & 34.6 & 17.3 \\
\hline Horticulture & 41.2 & 41.2 & 44.3 & 42.9 \\
\hline Permanent crops & 51.2 & 41.7 & 41.2 & 34.8 \\
\hline Grazing livestock & 49.6 & 35.1 & 47.1 & 33.1 \\
\hline Granivores & 71.5 & 67.4 & 70.5 & 67.0 \\
\hline Mixed & 31.0 & 20.3 & 28.2 & 18.8 \\
\hline \multicolumn{5}{|l|}{ Geographical location } \\
\hline Northern and Central Italy & 46.7 & 36.3 & 41.8 & 32.6 \\
\hline Southern Italy & 44.1 & 30.7 & 39.6 & 26.5 \\
\hline \multicolumn{5}{|l|}{ Farm size } \\
\hline Less than 5 hectares & 27.9 & 26.9 & 23.8 & 22.7 \\
\hline 5-15 hectares & 37.8 & 30.9 & 33.7 & 28.4 \\
\hline $15-40$ hectares & 45.2 & 31.7 & 40.1 & 29.2 \\
\hline More than 40 hectares & 72.1 & 46.9 & 66.4 & 39.8 \\
\hline \multicolumn{5}{|l|}{ Farmer's gender } \\
\hline Male & 48.2 & 36.1 & 43.4 & 32.1 \\
\hline Female & 36.5 & 26.5 & 32.3 & 23.0 \\
\hline \multicolumn{5}{|l|}{ Farmer's age } \\
\hline Up to 40 years old & 50.0 & 38.0 & 48.0 & 37.5 \\
\hline 41-65 years old & 47.5 & 35.5 & 43.2 & 31.8 \\
\hline 66 years old or more & 38.1 & 27.8 & 30.8 & 21.6 \\
\hline \multicolumn{5}{|l|}{ Farmer's Education level } \\
\hline Less than primary and lower secondary education & 40.5 & 29.7 & 36.5 & 26.7 \\
\hline Upper secondary, post-secondary non-tertiary education level & 50.3 & 38.2 & 45.5 & 33.8 \\
\hline Tertiary education level & 55.3 & 40.2 & 45.2 & 32.3 \\
\hline \multicolumn{5}{|l|}{ Off-farm Gainful Activities } \\
\hline Yes & 36.2 & 24.9 & 27.6 & 17.6 \\
\hline No & 46.4 & 34.7 & 42.0 & 31.2 \\
\hline \multicolumn{5}{|l|}{ Level of farmer's engagement } \\
\hline Regularly employed on farm & 47.2 & 35.5 & 43.1 & 32.1 \\
\hline Not regularly employed on farm & 32.8 & 22.2 & 23.6 & 14.2 \\
\hline
\end{tabular}

The levels of the short-term viability depend on structural, productive and social characteristics.

By applying Kruskal-Wallis and U Mann-Whitney tests, the hypothesis of equal distribution of the index among different categories within each variable was rejected with the exception of geographical location (Table A3, Appendix A). Therefore, the distribution of the viability index does not differ between Central-Northern and Southern Italy, while it is statistically different in relation to other variables. 
The Profitability Index (PI), estimated as the ratio of the FNI recorded in the FADN and the reward of household's owned factors at their opportunity costs, gives additional insights on the long-term viability of the farm. The mean value of the Profitability Index is 1.19 (Table A2, Appendix A) and then, on average, the farmer's factors are remunerated at their opportunity cost. When the profitability index is below 1 , the farm is unable to remunerate its factors at the opportunity cost and is therefore likely not to be sustainable in the long term. This happens in $59 \%$ of the sample as a whole, a share that increases to $70 \%$ when EU aids are deducted from the Farm Net Income. The share of long-term viable farms varies according to specific structural and socio-demographic characteristics (Table 2). It increases with the size class $(24 \%$ in the group with less than 5 hectares, while $66 \%$ of farms with more than 40 hectares), in relation to the farmer's education level (36\% of farms when the farmer has a primary and lower secondary education level, $45 \%$ for higher education levels), the higher is the farmer commitment on farm ( $24 \%$ of cases when the farmer is not regularly employed on the farm, $43 \%$ in the case of regular engagement), the younger is the farmer ( $30.8 \%$ if the farmer is over 65 years old and $48 \%$ when farmers are 40 years old or less). The distribution of the profitability index is statistically different in relation to the analysed variables, with the exception of geographical location (Table A4, Appendix A).

By taking into account both the Viability Index that accounts for the "fairness" of agricultural income in relation to the average income of the economy (short-term viability) and the Profitability Index as indicator of long-term viability/sustainability, four different situations can be considered both with and without CAP support (Table 3).

Table 3. Classification of Farm Accountancy Data Network sample according to short-term viability and the profitability index both with and without Common Agricultural Policy aids.

\begin{tabular}{|c|c|c|c|c|}
\hline & \multicolumn{4}{|c|}{ Viability Groups } \\
\hline & $\begin{array}{l}\text { Viable in the Short } \\
\text { and Long Term }\end{array}$ & $\begin{array}{l}\text { Viable in the Short Term but } \\
\text { Unviable in the Long Term }\end{array}$ & $\begin{array}{l}\text { Unviable in the Short Term } \\
\text { but Viable in the Long Term }\end{array}$ & $\begin{array}{l}\text { Unviable in the Short } \\
\text { and Long Term }\end{array}$ \\
\hline & \multicolumn{4}{|c|}{ With CAP aids } \\
\hline Number of farms & 2361 & 498 & 203 & 3208 \\
\hline \multirow[t]{2}{*}{ Percentage of the sample (\%) } & 37.7 & 7.9 & 3.2 & 51.2 \\
\hline & \multicolumn{4}{|c|}{ Without CAP aids } \\
\hline Number of farms & 1709 & 421 & 178 & 3962 \\
\hline Percentage of the sample (\%) & 27.3 & 6.7 & 2.8 & 63.2 \\
\hline
\end{tabular}

When the viability is assessed including CAP aids in the value of FNI, a first group includes 1709 farms that are viable both in the short and medium-long term (37.7\% of the sample). In this group, agricultural activities guarantee a fair income for the family and, at the same time, are able to remunerate family factors at their opportunity cost. Table 4 can help to better define structural variables that characterize this one and the other groups. Moreover, structural features have proved to be statistically different across groups (Table A5, Appendix A).

Table 4. Mean values of structural characteristics by short and long-term viability groups.

\begin{tabular}{|c|c|c|c|c|}
\hline & \multicolumn{4}{|c|}{ Viability Groups } \\
\hline & $\begin{array}{l}\text { Viable in the Short } \\
\text { and Long Term }\end{array}$ & $\begin{array}{l}\text { Viable in the Short Term but } \\
\text { Unviable in the Long Term }\end{array}$ & $\begin{array}{l}\text { Unviable in the Short Term } \\
\text { but Viable in the Long Term }\end{array}$ & $\begin{array}{l}\text { Unviable in the Short } \\
\text { and Long Term }\end{array}$ \\
\hline FNI per Family Work Unit (euro) & 82,752 & 32,624 & 19,010 & 9156 \\
\hline Family Work Units $\left(\mathrm{n}^{\circ}\right)$ & 1.5 & 0.9 & 2.2 & 1.1 \\
\hline Share of family work & $75.8 \%$ & $84.5 \%$ & $91.8 \%$ & $93.7 \%$ \\
\hline Utilised Agricultural Area (hectares) & 51.0 & 34.1 & 40.8 & 18.4 \\
\hline $\begin{array}{l}\text { Value Added per UAA } \\
\text { (euro/hectare) }\end{array}$ & 11,176 & 4977 & 9700 & 4397 \\
\hline Share of other on-farm revenues (\%) & 6.7 & 4.1 & 4.6 & 3.1 \\
\hline $\begin{array}{l}\text { Share of revenues from processed } \\
\text { products or direct sales (\%) }\end{array}$ & 17.6 & 13.0 & 18.4 & 16.2 \\
\hline Working capital value (euro) & 139,108 & 47,926 & 69,730 & 33,457 \\
\hline Share of CAP aids on FNI (\%) & 22.1 & 37.5 & 30.0 & 46.9 \\
\hline
\end{tabular}


This group represents the most professional component of Italian agriculture. The level of professionalism is associated with the high level of farm employment (2.5 AWU), greater recourse to hired labour, and thus lower share of family labour with respect to other groups (on average 1.5 family AWU, the $76 \%$ of total farm employment), and higher working capital invested. Farms in this group have an average Utilised Agricultural Area (UAA) that exceeds 50 hectares, have a large share of irrigated land ( $42 \%$ on average), the larger share of revenues related to diversification strategies, and show high levels of land and labour productivity, expressed in Value Added per UAA and work unit respectively, equal on average to 11.2 and 60.5 thousand euros, higher than other groups.

A second group of farms is composed of $7.9 \%$ of the sample and includes situations where agricultural activity is able to provide the reference income, but does not remunerate family resources at their opportunity cost (viable in the short term but not in the medium-long term). That can mainly be due to the large value of land investments and more extensive farming systems. As a fact, this group includes medium and large farms (34 hectares on average) with low levels of farm employment, and land and labour productivity lower than the previous group (Table 4). In almost two thirds of cases, viability is guaranteed by EU aid, which on average accounted for $37.5 \%$ of the Farm Net Income in the 2015-2017 period.

The other two groups have very different characteristics. The third group includes very few farms (203 farms; 3.2\% of the sample) which do not guarantee to the family a fair income but remunerate their resources at the opportunity cost (not viable in the short-term but viable in the long-term). This apparent contradiction depends on the way the reference income has been fixed: while in the short term the focus is on average earnings in the economy as a whole and the viability reflects the social fairness of the family income, in the long term, the family labour remuneration is assessed with reference to the agricultural wage. Moreover, in this group the family is largely engaged in the farm activity and the high level of employment (2.5 AWU on average) is mainly represented by family labour force. On the other side, the farm's assets are the lowest among groups.

The last group of farms includes more than $50 \%$ of the sample and the most critical situations. In fact, these farms are unviable in the short and in the medium-long term, therefore they do not guarantee a comparable income and do not remunerate family resources at their opportunity cost. Although there is great variability within the group, some main features can be highlighted. Firstly, EU aids represent on average $47 \%$ of net income, which is the highest percentage compared to other groups. Secondly, the average farm size is equal to 18 hectares, but in more than $25 \%$ of the group, the UAA is lower than 5 hectares. Moreover, the factors productivity is the lowest in the sample.

A final point to highlight is the change in groups consistency when CAP support is abolished. In fact, without CAP payments, farms that remain viable in the short and medium-long term decrease from $37.7 \%$ to $27.3 \%$ of the sample. Therefore, $27 \%$ of farms that are viable when CAP payments are included in their FNI lose their viability if aids are removed. A large share of them (40\%) is represented by large Fieldcrops farming system, which benefit to a large extent from EU support.

On the other side, the most vulnerable area, the unviable farms both in the short and medium-long term, increases from 3208 to 3962 farms, from $51.2 \%$ to $63.2 \%$ of the sample (Table 3). These figures are very striking as they highlight how relevant is the income issue in the agricultural sector.

\subsection{Viability Factors}

In developing the econometric model, a wide set of independent variables belonging to the three macro-categories indicated above (socio-demographic, structural, and economic choices) has been considered. Through a stepwise reduction, the most parsimonious form of the model is therefore presented, which shows only the statistically significant variables.

As discussed above (see Table 3), with CAP payments, $2361 \mathrm{farms} \mathrm{(37.7 \%} \mathrm{of} \mathrm{the} \mathrm{sample)} \mathrm{can} \mathrm{be}$ classified as viable both in the short and medium-long term. Yet, without EU aids, 652 farms no longer meet the criterion of viability (in the short and medium-long term). Consequently, fully viable farms fall to 1709 (27.3\% of the sample). In the two models, the overall sample of farms is the same and the 
independent variables as well. Only the criterion for assigning farms to the four groups (viable in the short and medium-long term, viable in the short term but not in the long term, unviable in the short but not viable in the long term, non-viable farms) is different, since Model 1 calculates viability with EU aids and Model 2 without EU aids.

Table 5 summarize the results of the multinomial logit model with CAP Aids. Tables A6-A9 (Appendix A) describe the multinomial logit without CAP Aids, the variables used in the final analysis and the estimated coefficients. By looking at Table 5, some variables are statistically related to all farm categories, so we can consider them as indicators of viability in all the different scenarios of short and medium-long term. Among these variables, the geographical area identified by the variable Geographical Location shows a Relative Risk Ratio (RRR) below 1 for all the viability states, indicating that farms located in Southern Italy are associated with a lower probability of being viable. More in detail, it can be observed the RRRs highlight a reduction of the probability of being viable of almost $30 \%$ in every category. This is consistent with the economic divide that characterizes the two Italian macro-areas and with previous studies that underline the role of the territory in influencing the firms' competitiveness [35,36].

Table 5. Multinomial Logit Model results.

\begin{tabular}{|c|c|c|c|}
\hline \multicolumn{4}{|c|}{ Model with CAP Aids } \\
\hline & Viable Short and Long & Unviable Short but Viable Long & Viable Short but Unviable Long \\
\hline & Relative Risk Ratio & Relative Risk Ratio & Relative Risk Ratio \\
\hline Gender & $0.763^{* * *}(0.060)$ & $0.816(0.153)$ & $0.845(0.104)$ \\
\hline Age & $0.981^{* * *}(0.002)$ & $0.979^{* * *}(0.005)$ & $1.004(0.003)$ \\
\hline Geographic Location & $0.703^{* * *}(0.049)$ & $0.692 *(0.114)$ & $0.689^{* * *}(0.075)$ \\
\hline Share of other on-farm revenues & $1.996^{* * *}(0.425)$ & $1.543(0.714)$ & $1.776(0.536)$ \\
\hline Granivores & $4.347^{* * *}(0.780)$ & $1.739(0.738)$ & $0.953(0.336)$ \\
\hline $\begin{array}{l}\text { Share of revenues from processed } \\
\text { products or direct sales }\end{array}$ & $1.467^{* * *}(0.138)$ & $1.619 *(0.314)$ & $0.873(0.147)$ \\
\hline Capital Intensity & $1.011^{* * *}(0.003)$ & $1.015^{* * *}(0.003)$ & $1.004(0.004)$ \\
\hline Share of Family Work & $0.033^{* * *}(0.005)$ & $0.638(0.286)$ & $0.091^{* * *}(0.022)$ \\
\hline Share of Irrigated UAA & $2.513^{* * *}(0.205)$ & $1.851^{* * *}(0.346)$ & $1.608^{* * *}(0.203)$ \\
\hline UAA1 ( $>5$ and $\leq 15$ hectares) & $2.618^{* * *}(0.268)$ & $1.287(0.308)$ & $1.242(0.191)$ \\
\hline UAA2 ( $>15$ and $\leq 40$ hectares) & $3.986^{* * *}(0.441)$ & $2.412 * * *(0.594)$ & $1.993^{* * *}(0.322)$ \\
\hline UAA3 (>40 hectares) & $15.867^{* * *}(1.924)$ & $7.904^{* * *}(1.996)$ & $5.395^{* * *}(0.927)$ \\
\hline Cons & $7.740 * * *(1.982)$ & $0.122^{* * *}(0.076)$ & $0.608(0.235)$ \\
\hline
\end{tabular}

Dependent Variable: Farms Viability; Base = Unviable in the short and medium-long run; Standard Deviations are presented in brackets; Number of obs. =6270; LR $\chi^{2}(12)=1942.44 ;$ Prob $>\chi^{2}=0.0000 ;$ Log likelihood $=-5437.3918$; Pseudo-R $\mathbb{R}^{2}=0.1515 ;{ }^{*} p \leq 0.05 ;{ }^{* *} p \leq 0.01 ;{ }^{* * *} p \leq 0.001$.

Farm size refers to structural characteristics and also plays a crucial role in determining the probability of being viable. Indeed, RRRs shows that as firms' size grows, the probability of being viable increases. This is particularly clear in the case of firms with more than 40 ha where the probability of being viable in the short and medium-long term is 15 times higher when compared to firms with less than 5 ha. As the size grows, the statistically significant relationship extends to all categories of viability. The last variable influencing viability in all the categories considered is the share of irrigated land. As largely expected, this variable more than doubles the probability of being viable in the scenarios where the viability of long term is considered. Indeed, the share of irrigated land is a characteristic that can be associated to a higher quality of the natural resources and plays a relevant role because it also affects the production of more intensive and profitable crops, increasing the revenues and supporting farm viability in the long period.

Other variables show statistically significant effects only for some categories. Likelihood of being viable, at least in the long term, is positively influenced by the capital intensity as well as by the share of revenues from processed products or direct sales, that summarize the entrepreneurial choice to focus on forwards activities in the supply chain and increases the likelihood of being sustainable. Referring to the farming system, Granivores are associated with an increase in the probability of being viable in the short and long term. In particular, the RRR of being viable in the short and long term is 3 times higher when compared to other farming systems. 
Results also suggest that socio-demographic variables affect the viability to some extent: age is associated to a higher probability of being an unviable farm for the two categories which consider the long-term viability, while female gender is associated with a reduction of $30 \%$ of the probability of being viable in both the long and short term.

Finally, the share of family work is negatively correlated with the probability of being viable; in fact, the RRR is below 1. This happens for both the first category (Viable in the Short and Long Term) and the third category (Viable in the Short but Unviable in the Long Term). It is therefore possible that the under-remuneration of family work makes negative the Viability index (VI).

Results of Model 1 are also overall confirmed in the scenario without CAP Aids (Table A7, Appendix A) since all the regressors previously used in Model 1 are significant and show an analogue sign of the coefficient. Nevertheless, some substantial differences can be observed among coefficients values of several variables, as it is shown in Tables 5 and A7. For this reason, a Seemingly Unrelated Estimation (SUEST) test has been performed (Table 6). Test results suggest a potential distortive effect of EU policies and aids that rewards larger farms the most. As a matter of fact, the differences in terms of the probability of being viable in the short- and long-term increase with size of the farms, from 0.2 to 1.36. A similar trend, albeit more uncertain, can be observed in the other categories of viability considered. Along other significant variables, capital intensity and farming systems requiring high capital intensity, such as Granivores, seem to be slightly favored in the non-aid scenarios. This suggests that, if EU aid is not more granted, structural characteristics are expected to be more stringent to farm viability.

Table 6. Test for coefficient differences.

\begin{tabular}{|c|c|c|c|}
\hline & \multicolumn{3}{|c|}{ Differences between Models' Coefficient (Model 1 - Model 2) } \\
\hline & Viable Short and Long & Unviable Short but Viable Long & Viable Short but Unviable Long \\
\hline Gender & 0.041 & -0.167 & -0.105 \\
\hline Geographical location & 0.080 & 0.245 & 0.009 \\
\hline Share of other on-farm revenues & -0.070 & -0.211 & 0.410 \\
\hline Granivores & $-0.196^{* *}$ & -0.305 & -0.336 \\
\hline Capital Intensity & $-0.005^{* * *}$ & $-0.004^{* * *}$ & -0.004 \\
\hline Share of Family Work & -0.517 & -0.491 & -0.072 \\
\hline Share of Irrigated area & -0.029 & -0.245 & -0.054 \\
\hline UAA1 ( $>5$ and $\leq 15$ hectares) & $0.206^{* * *}$ & 0.022 & $0.410^{* * *}$ \\
\hline UAA2 ( $>15$ and $\leq 40$ hectares) & $0.528^{* * *}$ & $0.366^{*}$ & $0.796^{* * *}$ \\
\hline
\end{tabular}

\section{Discussion and Conclusions}

The focus of this study was to assess to which extent agricultural activities guarantee fair levels of income to farmers and the role CAP payments play in determining the economic viability of Italian farms. Moreover, it aimed at exploring socio-economic factors associated with farm viability to provide some insights on the most vulnerable components of Italian agriculture and on fields of potential intervention.

Our findings highlight how relevant the income issue is in the Italian agricultural sector. Farms that are unviable both in the short and medium-long term represent $51.2 \%$ of the sample under analysis and their share increases to $63.2 \%$ when the income is net of CAP aids.

As factors affecting farm viability are concerned, we found that both structural farm characteristics and farmer's production strategies explain the likelihood of a farm to be viable in the short and in the medium-long term. Our findings confirm the results of previous studies with respect to the influence of factors that affect farm economic performance through the productivity, such as farm size, capital intensity, and land quality $[6,44]$. Moreover, in line with the literature results $[38,45,46]$, 
viability can be guaranteed by differentiation strategies of on-farm activities, as well as by vertical integration of forward processing activities and the development of short chains.

Farmers' features are relevant, too. In particular, the older the farmer is, the lower the likelihood is of the farm to be viable. That could depend on the lower propensity to invest and innovate as the farmer gets older [47], and the consequent lower ability to adapt to market changes, but it could also be linked to a different role agricultural activities can play in ensuring an adequate income level when pensions are added up. A different role of farm revenues for the household incomes could also explain why the likelihood of a farm to be viable decreases when the holder is a woman [27].

Therefore, farm viability is affected by a set of socio-economic and structural variables that can be directly or indirectly related to the factors' productivity, on one side, and to the role the agricultural activity plays for the household incomes, on the other side. As a fact, the rural households can sum up non-agricultural sources of income, such as pensions or rents, farming activity can be a farmer second activity, and the household can integrate off-farm incomes of one family member and on farm income of another component. Therefore, the weight of the agricultural activities on the household income can be different according to the family characteristics. Sometimes the farm could have an ancillary role in the family income and that could explain the persistence of otherwise unviable situations.

CAP payments do not modify the factors that affect farm viability but can change their weight. In particular, without CAP aids, the effect of the farm's size on viability significantly decreases, so highlighting the unfair present support system, while capital intensity becomes a more relevant factor in discriminating viable farms, suggesting the need of the policy to strongly focus on the structural change to guarantee adequate incomes and the economic sustainability of rural communities.

In conclusion, the analysis of Italian FADN sample highlighted two main points. First, it exists a core of farms where the agricultural activity is able to guarantee to farmer and his/her family an income level equal or higher than an average reference income, shows high levels of labour productivity, and remunerates the household's resource at their opportunity cost. However, more than $25 \%$ of farms within this group could fall below the economic viability threshold if CAP aids were removed. Several structural and economic factors could explain this result, but there is no doubt that EU support has been a kind of "artificial food" that has kept alive otherwise critical situations, slowing down a necessary restructuring process. Indeed, so far farm's income support and the EU investment policy have run on parallel tracks with the financial prevalence of the first one and an amount of resources allocated to investments very small compared to income support. This policy has generated an area of high vulnerability and an unstable balance. CAP post-2020 proposals are not facing this issue, but some way should be found to link income support to the structural change and to objectives of farm development.

A second point to underline is the large share of Italian agriculture that is far from being viable in the short as well as in the long term. This group includes several different situations and farm typologies: part time farmers with off-farm gainful activities, farms where the holder is a woman and where the agricultural activity integrates other family incomes, old farmers who sum agricultural incomes and pensions, small-sized farms or farms localized in disadvantaged areas characterized by low productivity resources. In several of these cases, the agricultural income is only a small share of the family income; in other situations, the agricultural income is too low to think to the farm from an economic perspective. These situations are at risk if the income support will be aimed to genuine farmers as the post-2020 proposals suggest and are representative of the conflict among post-2020 CAP objectives, that is, competitiveness versus fair income and environmental protection. The income support keeps a set of otherwise unviable, not competitive farms, but at the same time allows for maintaining the viability of the rural areas and protecting and conserving the countryside. To deal with this conflict, a more careful analysis of the different situations included in the unviable group would help to better identify the need of intervention and to maximize the effectiveness of the policies (CAP but other policies, too). 
Author Contributions: Although this work is the result of a common effort, A.C. was overall responsible for the supervision and conceptualization of the work and took the lead in organizing the structure of the manuscript. A.C. conceived and wrote Sections 1 and 2; A.C. and A.S. have contributed in the data collection and wrote Sections 3.1 and 3.2. M.A. and F.V. wrote Sections 3.3 and 4, analysed data, and presented results. A.C. conceived and wrote Section 5. All authors have contributed in critically reviewing and editing the manuscript. All authors have read and agreed to the published version of the manuscript.

Funding: This research received no external funding.

Conflicts of Interest: The authors declare no conflict of interest.

\section{Appendix A}

Table A1. Share of EU aids on FNI-Results of Kruskal-Wallis tests on farming systems and farm's size.

\begin{tabular}{ccc}
\hline & Kruskal-Wallis & Sig. \\
\hline Farming systems & 1226 & 0.000 \\
Farm Size & 1287 & 0.000 \\
\hline
\end{tabular}

Table A2. Descriptive statistics of Viability and Profitability indexes.

\begin{tabular}{|c|c|c|c|c|}
\hline Index & Min & Max & Mean & Std Deviation \\
\hline Viability index (including CAP payments) & $-219,641$ & $6,004,696$ & 22,445 & 135,915 \\
\hline Viability Index (excluding CAP payments) & $-234,460$ & $4,433,532$ & 10,347 & 115,865 \\
\hline Profitability index (including CAP payments) & -6.16 & 16.84 & 1.19 & 1.36 \\
\hline Profitability index (excluding CAP payments) & -6.69 & 18.45 & 0.88 & 1.26 \\
\hline
\end{tabular}

Table A3. Viability Index-Results of Kruskal-Wallis tests (k-samples) and U Mann-Whitney test (2-samples).

\begin{tabular}{ccc}
\hline & Kruskal-Wallis & Sig. \\
\hline Farming systems & 224.681 & 0.000 \\
Farm Size & 665.454 & 0.000 \\
Farmer's education level & 80.376 & 0.000 \\
Farmer's age & 34.969 & 0.000 \\
\hline & U di Mann-Whitney & Sig. \\
\hline Geographical location & $4,770,909$ & 0.892 \\
Farmer's gender & $2,897,817$ & 0.000 \\
Off-farm gainful activities & $1,333,622$ & 0.038 \\
Level of farmer's engagement & $1,792,740$ & 0.000 \\
\hline
\end{tabular}

Table A4. Profitability Index-Results of Kruskal-Wallis tests (k-samples) and U Mann-Whitney test (2-samples).

\begin{tabular}{ccc}
\hline & Kruskal-Wallis & Sig. \\
\hline Farming systems & 260.228 & 0.000 \\
Farm Size & 697.276 & 0.000 \\
Farmer's education level & 50.371 & 0.000 \\
Farmer's age & 94.788 & 0.000 \\
\hline & U di Mann-Whitney & Sig. \\
\hline Geographical location & $4,729,213$ & 0.468 \\
Farmer's gender & $2,879,713$ & 0.000 \\
Off-farm gainful activities & $1,124,283$ & 0.000 \\
Level of farmer's engagement & $1,439,654$ & 0.000 \\
\hline
\end{tabular}


Table A5. Results of Kruskal-Wallis tests on structural differences across farms' groups distinguished by Viability and Profitability indexes including CAP aids.

\begin{tabular}{ccc}
\hline & Kruskal-Wallis Test & Sig. \\
\hline FNI per Family Work Unit & 4890.62 & 0.000 \\
Annual Work Units & 1221.07 & 0.000 \\
Family Work Units & 701.84 & 0.000 \\
Share of family work & 812.87 & 0.000 \\
UAA & 639.21 & 0.000 \\
Share of irrigated land & 115.35 & 0.000 \\
Value added per work Units & 4052.32 & 0.000 \\
Value Added per UAA & 4052.32 & 0.000 \\
Share of other on-farm revenues & 79.42 & 0.000 \\
Working capital value & 36.1 & 0.000 \\
Share of revenues from processed products or direct sales & 569.85 & 0.000 \\
\hline
\end{tabular}

Table A6. Variables used in the final multinomial logit models.

\begin{tabular}{|c|c|}
\hline Variable & Description \\
\hline Gender & Dummy variable ( $1=$ female, $0=$ male $)$ \\
\hline Age & Age of the farmer. This is a continuous variable (number of years) \\
\hline Geographical location & $\begin{array}{l}\text { Dummy variable, which assumes value } 1 \text { when the farm is located in Southern Italy and } \\
0 \text { otherwise }\end{array}$ \\
\hline Share of other on-farm revenues & $\begin{array}{l}\text { Continuous variable that represents the share of Revenues from Complementary Activities on } \\
\text { Total Farm Revenues }\end{array}$ \\
\hline Granivores & $\begin{array}{l}\text { Dummy variable which assumes value } 1 \text { if the farm is specialized in granivores cultivation, } \\
0 \text { otherwise }\end{array}$ \\
\hline Share of revenues from processed products or direct sales & $\begin{array}{l}\text { Continuous variable that represents the share of revenues from practices that internalize } \\
\text { processing and distribution within the farm (e.g., direct sale); }\end{array}$ \\
\hline Capital intensity & $\begin{array}{l}\text { Continuous variable given by the ratio of the working capital value on Utilized Agricultural } \\
\text { Area (UAA) }\end{array}$ \\
\hline Share of family work & Continuous variable that represents the share of family Work Units on farm Total Work Units \\
\hline Share of Irrigated area & Continuous variable given by the ratio of Irrigated Area on Utilised Agricultural Area \\
\hline UAA = Utilised Agricultural Area & $\begin{array}{l}\text { Three dummy variables represent the size of the farm. UAA } 1 \text { assumes value } 1 \text { if the UAA is } \\
\text { between } 5 \text { and } 15 \text { hectares, UAA } 2 \text { assumes value } 1 \text { if the UAA is between } 15 \text { and } 40 \text { hectares, } \\
\text { UAA } 3 \text { assumes value } 1 \text { if the UAA of the farm is more than } 40 \text { hectares. }\end{array}$ \\
\hline
\end{tabular}

Table A7. Multinomial Logit Model results.

\begin{tabular}{cccc}
\hline & Model without CAP Aids & \\
\hline & Viable Short and Long & Unviable Short but Viable Long & Viable Short but Unviable Long \\
\hline & RRR & RRR & RRR \\
\hline Gender & $0.732^{* * *}(0.061)$ & $0.964(0.187)$ & $0.938(0.122)$ \\
\hline Age & $0.978^{* * *}(0.002)$ & $0.970^{* * *}(0.005)$ & $1.003(0.004)$ \\
\hline Geographical location & $0.649^{* * *}(0.047)$ & $0.541^{* * *}(0.099)$ & $0.683^{* * *}(0.079)$ \\
\hline Share of other on-farm revenues & $2.140^{* * *}(0.448)$ & $1.905(0.699)$ & $1.178(0.494)$ \\
\hline Granivores & $5.289^{* * *}(0.894)$ & $2.359^{*}(0.888)$ & $1.334(0.475)$ \\
\hline $\begin{array}{c}\text { Share of revenues from processed } \\
\text { products or direct sales }\end{array}$ & $1.616^{* * *}(0.151)$ & $2.084^{* * *}(0.369)$ & $0.956(0.168)$ \\
\hline Capital Intensity & $1.016^{* * *}(0.003)$ & $1.019^{* * *}(0.003)$ & $1.008(0.004)$ \\
\hline Share of Family Work & $0.056^{* * *}(0.008)$ & $1.042(0.461)$ & $0.098^{* * *}(0.022)$ \\
\hline Share of Irrigated UAA & $2.586^{* * *}(0.209)$ & $2.365^{* * *}(0.434)$ & $1.697^{* * *}(0.220)$ \\
\hline UAA1 $>5$ and $\leq 15$ hectares $)$ & $2.130^{* * *}(0.224)$ & $1.259(0.304)$ & $0.824(0.133)$ \\
\hline UAA2 $>15$ and $\leq 40$ hectares $)$ & $2.350^{* * *}(0.268)$ & $1.673^{*}(0.434)$ & $0.899(0.157)$ \\
\hline UAA3 $(>40$ hectares $)$ & $4.080^{* * *}(0.488)$ & $3.898^{* * *}(0.999)$ & $2.446^{* * *}(0.409)$ \\
\hline Cons & $4.859^{* * *}(1.206)$ & $0.090^{* * *}(0.057)$ & $0.525(0.204)$ \\
\hline
\end{tabular}

Dependent Variable: Farms Viability; Base = Unviable in the short and medium-long run; Standard Deviations are presented in brackets; Number of obs. $=6270 ;$ LR $\chi^{2}(12)=1510.03 ;$ Prob $>\chi^{2}=0.0000 ; \log$ likelihood $=-5049.6899$; Pseudo- $R^{2}=0.1301 ;^{*} p \leq 0.05 ;{ }^{* *} p \leq 0.01$; $^{* * *} p \leq 0.001$. 
Table A8. Estimated coefficients in multinomial logit model with CAP aids.

\begin{tabular}{|c|c|c|c|c|c|c|}
\hline \multicolumn{7}{|c|}{ Model with CAP Aids } \\
\hline & \multicolumn{2}{|c|}{ Viable Short and Long } & \multicolumn{2}{|c|}{ Unviable Short but Viable Long } & \multicolumn{2}{|c|}{ Viable Short but Unviable Long } \\
\hline & Coeff. & SD & Coeff. & SD & Coeff. & $\mathrm{SD}$ \\
\hline Age & $-0.019^{* * *}$ & 0.002 & $-0.021^{* * *}$ & 0.005 & 0.004 & 0.004 \\
\hline Geographical location & $-0.353^{* * *}$ & 0.070 & $-0.368^{*}$ & 0.169 & $-0.372^{* * *}$ & 0.108 \\
\hline $\begin{array}{l}\text { Share of revenues from processed } \\
\text { products or direct sales }\end{array}$ & $0.383^{* * *}$ & 0.105 & $0.482 *$ & 0.191 & -0.136 & 0.189 \\
\hline Capital Intensity & $0.011 * * *$ & 0.003 & $0.015^{* * *}$ & 0.004 & 0.004 & 0.008 \\
\hline Share of Family Work & $-3.398^{* * *}$ & 0.182 & -0.449 & 0.409 & $-2.391 * * *$ & 0.253 \\
\hline Share of Irrigated UAA & $0.922 * * *$ & 0.085 & $0.616^{* * *}$ & 0.186 & $0.475^{* * *}$ & 0.135 \\
\hline Cons & $2.047^{* * *}$ & 0.269 & $-2.103^{* * *}$ & 0.606 & -0.497 & 0.402 \\
\hline
\end{tabular}

Dependent Variable: Farms Viability; Base $=$ Unviable in the short and medium-long run; Number of obs. $=6270$; LR $\chi^{2}(12)=1942.44 ;$ Prob $>\chi^{2}=0.0000 ;$ Log likelihood $=-5437.3918$; Pseudo- $R^{2}=0.1515 ;{ }^{*} p \leq 0.05 ;{ }^{* *} p \leq 0.01$; $* * * \quad p \leq 0.001$.

Table A9. Estimated coefficients in multinomial logit model without CAP aids.

\begin{tabular}{|c|c|c|c|c|c|c|}
\hline & \multicolumn{2}{|c|}{ Viable Short and Long } & \multicolumn{2}{|c|}{ Unviable Short but Viable Long } & \multicolumn{2}{|c|}{ Viable Short but Unviable Long } \\
\hline & Coeff. & SD & Coeff. & SD & Coeff. & SD \\
\hline Gender & $-0.312^{* * *}$ & 0.083 & -0.036 & 0.195 & -0.064 & 0.130 \\
\hline Geographical location & $-0.433^{* * *}$ & 0.074 & $-0.613^{* * *}$ & 0.190 & $-0.381^{* * *}$ & 0.117 \\
\hline Share of other on-farm revenues & $0.761^{* *}$ & 0.348 & 0.645 & 0.424 & 0.164 & 0.406 \\
\hline Capital Intensity & $0.016^{* * *}$ & 0.004 & $0.019^{* * *}$ & 0.005 & 0.008 & 0.008 \\
\hline Share of Family Work & $-2.880^{* * *}$ & 0.157 & 0.042 & 0.411 & $-2.320^{* * *}$ & 0.228 \\
\hline Share of Irrigated UAA & $0.950 * * *$ & 0.087 & $0.861 * * *$ & 0.179 & $0.529^{* * *}$ & 0.135 \\
\hline UAA1 ( $>5$ and $\leq 15$ hectares) & $0.756^{* * *}$ & 0.105 & 0.231 & 0.243 & -0.193 & 0.159 \\
\hline
\end{tabular}

Dependent Variable: Farms Viability; Base $=$ Unviable in the short and medium-long run; Number of obs. $=6270$; LR $\chi^{2}(12)=1510.03 ;$ Prob $>\chi^{2}=0.0000$; Log likelihood $=-5049.6899 ;$ Pseudo- $R^{2}=0.1301 ;{ }^{*} p \leq 0.05 ;{ }^{* *} p \leq 0.01$; $* * * \quad p \leq 0.001$.

\section{References}

1. Vrolijk, H.C.J.; De Bont, C.J.; Blokland, P.W.; Soboh, R.A. Farm Viability in the European Union: Assessment of the Impact of Changes in Farm. Payments; Report 2010-011; LEI: Wageningen, The Netherlands, 2010.

2. Hill, B.; Bradley, B.D. Comparison of Farmers' Incomes in the EU Member States, Policy Department B: Structural and Cohesion Policies; European Parliament: Brussels, Belgium, 2015; Available online: http://www.europarl. europa.eu/RegData/etudes/STUD/2015/540374/IPOL_STU(2015)540374_EN.pdf (accessed on 5 January 2020).

3. Allanson, P.; Hubbard, L. On the comparative evaluation of agricultural income distributions in the European Union. Eur. Rev. Agric. Econ. 1999, 26, 1-17. [CrossRef]

4. European Commission. Modernising and Simplifying the CAP. Background Document. Economic Challenges Facing EU Agriculture; European Commission: Brussels, Belgium, 2017; Available online: https://ec.europa.eu/ agriculture/sites/agriculture/files/consultations/cap-modernising/soc_background_final_en.pdf (accessed on 2 January 2020). 
5. Ryan, M.; Hennessy, T.; Buckley, C.; Dillon, E.J.; Donnellan, T.; Hanrahan, K.; Moran, B. Developing farm-level sustainability indicators for Ireland using the Teagasc National Farm Survey. Ir. J. Agric. Food Res. 2016, 55, 112-125. [CrossRef]

6. Argilés, J.M. Accounting information and the prediction of farm non-viability. Eur. Account. Rev. 2001, 10, 73-105. [CrossRef]

7. De Frahan, B.H.; Dong, B.J.; De Blander, R. Farm Household Incomes in OECD Member Countries over the Last 30 Years of Public Support. In Public Policy in Agriculture. Impact on Labor Supply and Household Income; Mishra, A.K., Viaggi, D., Gomez y Paloma, S., Eds.; Routledge: London, UK, 2017; pp. 124-151.

8. Rocchi, B.; Stefani, G.; Romano, D.; Landi, C. Are Italian farming households actually poorer than other non agricultural households? An empirical analysis. In Proceedings of the Towards a Sustainable Bio-economy: Economic Issues and Policy Challenges, Trento, Italy, 4-5 June 2012.

9. Rocchi, B.; Marino, M.; Severini, S. Does a farm household income problem still exist in the European Union. In Proceedings of the Evidence-Based Policies to Face New Challenges for Agri-Food Systems, Conegliano (TV), Italy, 14-15 June 2018.

10. Hill, B. Farm Incomes, Wealth and Agricultural Policy_Filling the CAP's Core Information Gap, 4th ed.; CAB International: Oxfordshire, UK, 2012.

11. O’Donoghue, C.; Devisme, S.; Ryan, M.; Conneely, R.; Gillespie, P.; Vrolijk, H. Farm economic sustainability in the European Union: A pilot study. Stud. Agric. Econ. 2016, 118, 163-171. [CrossRef]

12. Spicka, J.; Hlavsa, T.; Soukupova, K.; Stolbova, M. Approaches to estimation the farm-level economic viability and sustainability in agriculture: A literature review. Agric. Econ.-Czech. 2019, 65, 289-297. [CrossRef]

13. Dillon, E.J.; Hennessy, T.; Hynes, W.E. Assessing the sustainability of Irish agriculture. Int. J. Agric. Sustain. 2010, 8, 131-147. [CrossRef]

14. Frawley, J.P.; Commins, P. The Changing Structure of Irish Farming, Trends Prospects. Rural Economy Research Series 1; Teagasc: Dublin, Ireland, 1996.

15. Hennessy, T.; Shresthra, S.; Farrel, M. Quantifying the viability of farming in Ireland: Can decoupling address the regional imbalances? Ir. Geogr. 2008, 41, 29-47. [CrossRef]

16. Casini, L.; Ciaccia, D.; Pizzoli, E.; Boncinelli, F. Il reddito delle famiglie agricole italiane: Stima e analisi. Econ. Dirit. Agroaliment. 2013, 18, 287-302.

17. Boncinelli, F.; Casini, L. A Comparison of the Well-Being of Agricultural and Non Agricultural Households Using a Multicriterial Approach. Soc. Indic. Res. 2014, 119, 183-195. [CrossRef]

18. Stejskal, L.; Stávková, J. Living conditions of Czech farmers according to the EU statistics on income. Agric. Econ.-Czech. 2010, 56, 310-316. [CrossRef]

19. European Court of Auditors (ECA). Measurement of Farm Incomes by the Commission. Special Report N. 14/2003; Court of Auditors of the European Communities: Luxembourg, 2003; Available online: https: //www.eca.europa.eu/Lists/ECADocuments/SR03_14/SR03_14_EN.PDF (accessed on 8 January 2020).

20. Tosco, D. Redditività e costi di produzione delle aziende agricole: Aspetti metodologici e procedure applicative. In Redditività e Costi di Produzione delle Aziende Agricole—Un'Analisi Basata sul Campione RICA; Coppola, A., Tosco, D., Eds.; Edizioni Scientifiche Italiane: Napoli, Italy, 2014; pp. 25-42.

21. Coppola, A.; Scardera, A.; Tosco, D. Economic profitability and long-term viability in Italian agriculture. Politica Agric. Internazionale 2013, 1, 71-84.

22. Carley, D.H.; Fletcher, S.M. Financial soundness of Southern dairy farmers participating in the dairy termination program. Agric. Financ. Rev. 1988, 48, 86-93.

23. Lines, A.E.; Zulauf, C.R. Debt-to-asset ratios of Ohio farmers: A polytomous multivariate logistic regression of associated factors. Agric. Financ. Rev. 1985, 45, 92-99.

24. Seok, J.H.; Moon, H.; Kim, G.; Reed, M.R. Is aging the important factor for sustainable agricultural development in Korea? Evidence from the relationship between aging and farm technical efficiency. Sustainability 2018, 10, 2137. [CrossRef]

25. Prokopy, L.S.; Floress, K.; Klotthor-Weinkauf, D.; Baumgart-Getz, A. Determinants of agricultural best management practice adoption: Evidence from the literature. J. Soil Water Conserv. 2008, 63, 300-311. [CrossRef]

26. Phillips, J.M. Farmer Education and Farmer Efficiency: A Meta-Analysis. Econ. Dev. Cult. Chang. 1994, 43, 149-165. [CrossRef] 
27. Gasson, R.; Winter, M. Gender Relations and Farm Household Pluriactivity. J. Rural Stud. 1992, 8, $387-397$. [CrossRef]

28. Udry, C.; Hoddinott, J.; Alderman, H.; Haddad, L. Gender differentials in farm productivity: Implications for household efficiency and agricultural policy. Food Policy 1995, 20, 407-423. [CrossRef]

29. Doss, C.R.; Morris, M.L. How does gender affect the adoption of agricultural innovations? Agric. Econ. 2000, 25, 27-39. [CrossRef]

30. Hansson, H. Are larger farms more efficient? A farm level study of the relationships between efficiency and size on specialized dairy farms in Sweden. Agric. Food Sci. 2008, 17, 325-337. [CrossRef]

31. Adelaja, A.O.; Rose, K.B. Farm viability revisited: A simultaneous-equation cash flow approach. Agric. Financ. Rev. 1988, 48, 10-24.

32. Hanrahan, L.; McHugh, N.; Hennessy, T.; Moran, B.; Kearney, R.; Wallace, M.; Shalloo, L. Factors associated with profitability in pasture-based systems of milk production. J. Dairy Sci. 2018, 101, 5474-5485. [CrossRef] [PubMed]

33. Latruffe, L.; Davidova, S.; Balcombe, K. Application of a double bootstrap to investigation of determinants of technical efficiency of farms in Central Europe. J. Prod. Anal. 2008, 29, 183-191. [CrossRef]

34. Kostov, P.; Davidova, S.; Bailey, A. Comparative Efficiency of Family and Corporate Farms: Does Family Labour Matter? J. Agric. Econ. 2019, 70, 101-115. [CrossRef]

35. Capello, R.; Caragliu, A.; Nijkamp, P. Territorial capital and regional growth: Increasing returns in Knowledge use. Tijdschr. Econ. Soc. Geogr. 2011, 102, 385-405. [CrossRef]

36. Esposti, R. Convergence and divergence in regional agricultural productivity growth: Evidence from Italian regions, 1951-2002. Agric. Econ. 2011, 42, 153-169. [CrossRef]

37. European Commission. EC agricultural policy for the 21st century. Eur. Econ. 1994, 4, 1-147.

38. Barnes, A.P.; Hansson, H.; Manevska-Tasevska, G.; Shrestha, S.S.; Thomson, S.G. The influence of diversification on long-term viability of the agricultural sector. Land Use Policy 2015, 49, 404-412. [CrossRef]

39. Van der Ploeg, J.D.; Roep, D. Multifunctionality and rural development: The actual situation in Europe. In Multifunctional Agriculture: A New Paradigm for European Agriculture and Rural Development, Chapter: 3; van Huylenbroeck, G., Durand, G., Eds.; Ashgate Publishers: Farnham, UK, 2003.

40. Agrosynergie. Evaluation of the Structural Effects of Direct Support. Final Report; European Commission: Brussels, Belgium, 2013; Available online: https://www.cogea.it/sites/default/files/fulltext_en\%281\%29.pdf (accessed on 2 February 2020).

41. Wooldridge, J. Econometric Analysis of Cross Section and Panel Data; The MIT Press: Cambridge, UK, 2001.

42. Long, S. Regression Models for Categorical and Limited Dependent Variables, Advanced Quantitative Techniques in the Social Sciences; SAGE Publications: London, UK, 1997.

43. Weesie, J. Seemingly unrelated estimation and the cluster-adjusted sandwich estimator. STATA Tech. Bull. 1999, 52, 34-47.

44. Blazejczy-Majka, L.; Kala, R.; Maciejewski, K. Productivity and efficiency of large and small field crop farms and mixed farms of the old and new EU regions. Agric. Econ. 2012, 58, 61-71.

45. Salvioni, C.; Henke, R.; Vanni, F. The impact of non-agricultural diversification on financial performance: Evidence from family farms in Italy. Sustainability 2020, 12, 486. [CrossRef]

46. Bartolini, F.; Andreoli, M.; Brunori, G. Explaining determinants of the on-farm diversification: Empirical evidence from Tuscany region. Bio-Based Appl. Econ. 2014, 3, 137-157.

47. Brown, P.; Daigneault, A.; Dawson, J. Age, values, farming objectives, past management decisions, and future intentions in New Zealand agriculture. J. Environ. Manag. 2019, 231, 110-120. [CrossRef] [PubMed]

(C) 2020 by the authors. Licensee MDPI, Basel, Switzerland. This article is an open access article distributed under the terms and conditions of the Creative Commons Attribution (CC BY) license (http://creativecommons.org/licenses/by/4.0/). 